\title{
FEA Analysis of FSAE Chassis
}

\author{
1. Rupesh Patil \\ 1.Engineering Student, \\ Dept. Mechanical Engineering. \\ Sinhgad Academy of Engineering \\ Pune, India
}

\author{
2. Vinayak Chikkali \\ 2.Engineering Student, \\ Dept. Mechanical Engineering \\ Sinhgad Academy of Engineering \\ Pune, India
}

\begin{abstract}
This Research Paper mainly presents an analysis of FSAE chassis. This chassis is design by conforming the rules of FSAE. The chassis frame is a main structural component to which all the other parts are attached. The chassis frame acts as the skeleton of the automobile so it should be able to withstand against various load condition. FEA Analysis Conforms ability to assess the forces and safety of design prior to manufacturing. Material Preferred for FSAE chassis is AISI4130 alloy of chromium and Molybdenum which has high strength as well as low weight. Analysis is done on standard Results to get maximum strength and minimum weight possible. Software tools used for analysis is Ansys.
\end{abstract}

Keywords- FSAE, Modal Analysis, FEA, AISI4130, Torsional Analysis

\section{INTRODUCTION}

SAE (society of automotive engineers) conducts the competition in which student build, design, and compete in formula student race car these help in providing the educational theory and hands on experience. Rules of SAE are analogous to code of conduct at work force it also incorporates the Team Work, Project management and Finance. The SAE competition is consisting of static and dynamic event where they are judge based on various parameters like conforming rules with performance of vehicle, team work and vehicle compliances. The main philosophy behind the analysis is to assure the driver safety in the cockpit. FEA Analysis is carried out by considering various Loads like bending, Torsional, Twisting, on Side Impact and Front Impact. FSAE chassis undergo various types of forces in dynamic event, FEA analysis helps to decide the manufacturing process has to carried out in order to make chassis as stiffer as possible with minimal cost. Material selection also plays a vital role in terms of strength, torsional rigidity. The paper focuses on the different configuration and actions of the chassis used in the FSAE competition when the chassis is used with front impact, side impact and torsional stiffness by the rules of the Formula SAE competition.

\section{METHODOLGY}

FINITE ELEMENT ANALYSIS (FEA) is carried out to determine the stiffness of chassis frame before construction. Conventionally in FEA, the frame is subdivided into elements. Nodes are placed where tubes of frame join. There are many types of elements possible for a structure and every choice the analyst makes can affect the results. The number, orientation and size of elements as well as loads and boundary conditions are all critical to obtain meaningful values of chassis stiffness. Beam elements are normally used to represent tubes. The assumption made in using beam elements is that the welded tubes have stiffness in bending and torsion. If a truss or link elements were used, the assumption being made would be that the connections do not offer substantial resistance to bending or torsion. Another aspect of beam element is the possibility of including transverse shearing effects. While modeling the stiffness contribution from each part of the frame, method to apply the loads and constrain the frame plays significant role for an accurate analysis. Accurate analysis means to predict the stiffness of frame close to actual stiffness as the frame operates in real conditions. The problem here has normally been how to constrain and load a frame, so to receive multiple load inputs from a suspension, while it has been separated from that suspension and many other such problems. For practical reasons, it is recommended that the load on the chassis frame, including its own weight should be applied at the joints (nodes) of structural members. These point loads were statistically equivalent to the actual distributed load carried by the vehicle. The analysis was done in Ansys R17.2. We choose to do 2D shell analysis as it gives appropriate result. Elements selected were 2D QUADS and 2D R-TRIAS. We also inserted dead mass to account for the inertia of the mass of engine.

\section{MATERIAL SELECTION}

Material selected for Chassis is AISI4130, also referred to as Chromyl Steel, is a chromium and molybdenum alloy steel Known for its responsiveness to mechanical and heat treatments. It is low carbon steel and offers lighter weight still maintain high strength. The mechanical properties of AISI4130 is listed in the following table.

\begin{tabular}{l}
\multicolumn{1}{|c|}{ TABLE 1 } \\
\begin{tabular}{|l|l|}
\hline \multicolumn{1}{|c|}{ Properties } & \multicolumn{1}{c|}{ Metric } \\
\hline Tensile Strength, Ultimate & $760 \mathrm{MPa}$ \\
\hline Tensile Strength, Yield & $435 \mathrm{MPa}$ \\
\hline Modulus of elasticity & $205 \mathrm{GPa}$ \\
\hline Bulk Modulus & $140 \mathrm{GPa}$ \\
\hline Poisson's Ratio & 0.29 \\
\hline
\end{tabular}
\end{tabular}

The Chemical Composition of AISI4130 is listed in the following table.

\begin{tabular}{|l|c|}
\multicolumn{2}{|c|}{ TABLE 2 } \\
\hline Iron, $\mathrm{Fe}$ & Content \% \\
\hline Chromium, $\mathrm{Cr}$ & $97.03-97.22$ \\
\hline Manganese, $\mathrm{Mn}$ & $0.80-1.10$ \\
\hline Molybdenum, Mb & $0.40-0.60$ \\
\hline Carbon, C & $0.15-0.25$ \\
\hline Silicon, Si & $0.280-0.330$ \\
\hline Sulphur, S & $0.15-0.30$ \\
\hline Phosphorous, $\mathrm{P}$ & 0.040 \\
\hline
\end{tabular}




\section{ANALYSIS}

Four types of analysis are performed on FSAE chassis. As Chassis undergo Bending due to weight of mounted components on Vehicle like engine, fuel tank, dampers etc. At dynamic event in FSAE, chassis evaluates for acceleration and cornering ability which leads to twist in chassis whereas it can be judge with the help of Torsional analysis. Types of Analysis performed are as follows.

1) Static Structural analysis

2) Torsional Analysis

3) Bending Analysis

4) Modal Analysis

Static Structural analysis are performed on two different cases of Chassis.

Two different cases are as follows

Case 1 Side Impact

Case 2 Front Impact

The FSAE car chassis must be rigid enough because it has to withstand vibration, twist, buckling, shock and many other stresses. Chassis must strong enough to allow adequate bending and torsion stiffness in order to improve the handling system.

\section{A. Case 1 Side Impact}

The velocity of car is assumed to be $70 \mathrm{~km} / \mathrm{hr}$. Side member of roll cage is in contact with wall. One side of the frame was constrained and calculated load was applied on the opposite side impact structure. Worst case considered is $4.5 \mathrm{G}$.

Parameters to be considered are shown in table below.

\begin{tabular}{|c|c|} 
TABLE 3 \\
\hline Parameters & Values \\
\hline Velocity & $46 \mathrm{Km} / \mathrm{hr}$ \\
\hline Car Weight & $220 \mathrm{Kg}$ \\
\hline Driver Weight & $60 \mathrm{Kg}$ \\
\hline
\end{tabular}

\section{Calculations}

The total force acting on the cockpit members was calculated using following empirical relations:

$>$ Final velocity $(\mathrm{v})=$ Initial velocity $(\mathrm{u})+$ acceleration (a) * time (t)

$>\quad 11.11=0+$ acceleration (a) $* 0.3$

$>$ Acceleration $(\mathrm{a})=37.03 \mathrm{~m} / \mathrm{s} 2$ (retarding -ve $\mathrm{X}$ axis)

$>$ Total force acting on the body $=$ Total mass of car $*$ Acceleration

$>$ Total force acting on the body $=280 * 37.03 \mathrm{~N}$

$$
=10368.4 \mathrm{~N} \text { (-ve } \mathrm{X} \text { axis) }
$$

This is the total calculated load, which has been acting on the side impact structure of FSAE chassis.

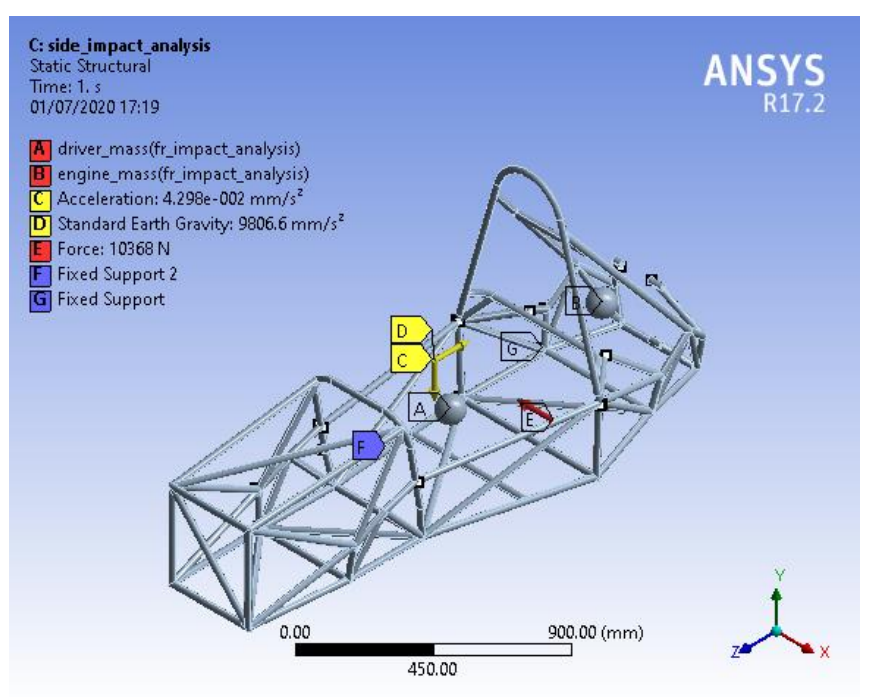

Figure 2 Boundary condition for Side Impact Structure

A boundary condition is a place on a structure where either the external force or the displacement are known at the start of the analysis. The boundary conditions are the places where the structure interacts with the environment either through the application of an external force or through some restraint that is imposing a displacement. For a structural analysis problem to be solvable, every location on the boundary of our structure must have a known boundary condition. For example, we may know that there are locations on our structure that have no external force. A displacement boundary condition that is zero is equivalent to the structure being held in place at that location. They simply impose deformations on boundaries in your model (usually equal to zero). Each point in space can translate in 3 directions and rotate around 3 axes.

\begin{tabular}{|c|c|c|}
\hline \multicolumn{3}{|c}{ TABLE 4 } \\
\hline \multicolumn{2}{|c|}{ Total Force on Side Impact Structure } & $\begin{array}{c}\text { 10368(on side impact } \\
\text { member -ve X axis) }\end{array}$ \\
\hline Boundary Conditions & $\begin{array}{c}\text { Translational } \\
\text { Displacement }\end{array}$ & $\begin{array}{c}\text { Rotational } \\
\text { Displacement }\end{array}$ \\
\hline \multirow{2}{*}{$\begin{array}{c}\text { Right Side front } \\
\text { Suspension }\end{array}$} & $\mathrm{X}=0$ & $\mathrm{X}=$ Fixed \\
\cline { 2 - 3 } & $\mathrm{Y}=0$ & $\mathrm{Y}=$ Fixed \\
\cline { 2 - 3 } & $\mathrm{Z}=0$ & $\mathrm{Z}=$ Fixed \\
\hline \multirow{2}{*}{$\begin{array}{c}\text { Right Side Rear } \\
\text { Suspension }\end{array}$} & $\mathrm{X}=0$ & $\mathrm{X}=$ Fixed \\
\cline { 2 - 3 } & $\mathrm{Y}=0$ & $\mathrm{Y}=$ Fixed \\
\cline { 2 - 3 }
\end{tabular}




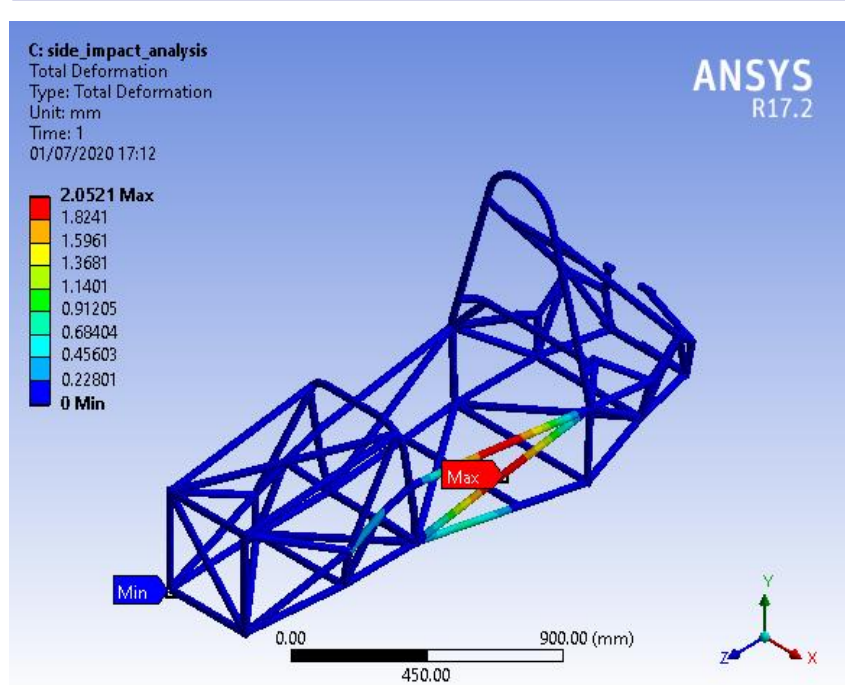

Figure 2 Deformation Analysis of Side Impact Structure

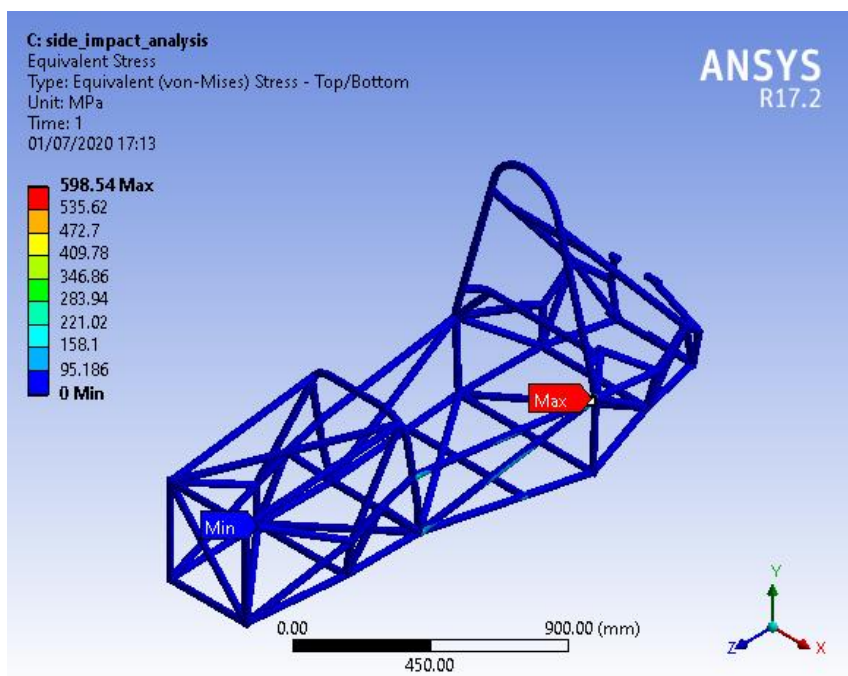

Figure 3 Von Mises Stress Analysis of Side Impact Structure

\section{Result}

TABLE 5

\begin{tabular}{|c|c|}
\hline Maximum Deformation & $2.0521 \mathrm{~mm}$ \\
\hline Von Misses Stress & $598.54 \mathrm{MPa}$ \\
\hline Factor of Safety & UTS/WS $=670 / 598.54=1.11$ \\
\hline
\end{tabular}

\section{B. Case 2 Front Impact Analysis}

The Front Impact Analysis is done to find out the amount of bending stress as well as deformation generated in the FSAE chassis if the car hits a solid body from the front whereas it is more likely to happen in any worst case. In order to Simulate the frontal impact crash, the vehicle was assumed to impact upon a stationary object. Upon research it was found that the maximum force that a human body can withstand is $5 \mathrm{G}$. For front Impact analysis suspension pick up point of the frame was Constrained and loads were applied at the fore most end. Worst case scenario considered for the analysis was $7.6 \mathrm{G}$

Parameters to be considered for calculations are given in table below
TABLE 6

\begin{tabular}{|c|c|}
\hline Parameters & Values \\
\hline Velocity & $85 \mathrm{Km} / \mathrm{hr}$ \\
\hline Car Weight & $220 \mathrm{Kg}$ \\
\hline Driver Weight & $60 \mathrm{Kg}$ \\
\hline
\end{tabular}

\section{Calculations}

The total force acting on the front bulkhead was calculated using following empirical relations:

$>$ Final velocity $(\mathrm{v})=$ initial velocity $(\mathrm{u})+$ acceleration (a) * time (t)

$>\quad 23.61=0+$ acceleration (a) $* 0.3$

$>$ Acceleration $(\mathrm{a})=-78.7 \mathrm{~m} / \mathrm{s}^{2}$ (retarding)

$>$ Total force acting on the body $=280 * 78.7 \mathrm{~N}$ $=22,036 \mathrm{~N}$ (-ve Z axis)

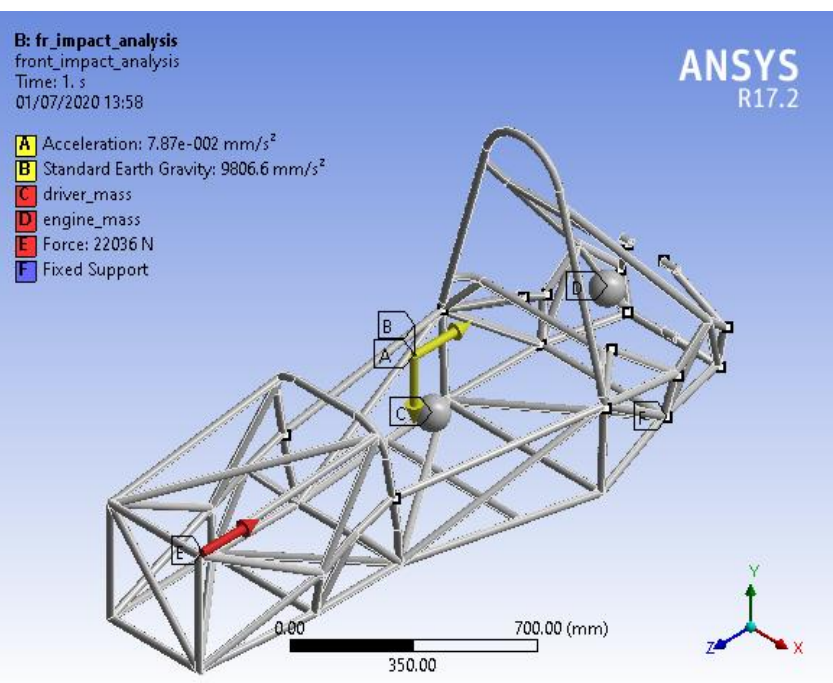

Figure 4 Boundary Conditions of Front Impact Structure

TABLE 7

\begin{tabular}{|c|c|c|}
\hline \multicolumn{2}{|c|}{$\begin{array}{c}\text { Total force acting on Front Impact } \\
\text { Structure }\end{array}$} & $\begin{array}{c}22036 \mathrm{~N} \text { (on front Impact } \\
\text { member-ve Z axis) }\end{array}$ \\
\hline \multirow{2}{*}{$\begin{array}{c}\text { Boundary } \\
\text { Condition }\end{array}$} & $\begin{array}{c}\text { Translational } \\
\text { Displacement }\end{array}$ & Rotational Displacement \\
\hline Front Suspension & $\mathrm{X}=$ Free & $\mathrm{X}=$ Free \\
\cline { 2 - 3 } & $\mathrm{Y}=$ Free & $\mathrm{Y}=$ Free \\
\cline { 2 - 3 } & $\mathrm{Z}=$ Free & $\mathrm{Z}=$ Free \\
\hline Rear Suspension & $\mathrm{X}=0$ & $\mathrm{X}=$ Fixed \\
\cline { 2 - 3 } & $\mathrm{Y}=0$ & $\mathrm{Y}=$ Fixed \\
\cline { 2 - 3 } & $\mathrm{Z}=0$ & $\mathrm{Z}=$ Fixed \\
\hline
\end{tabular}

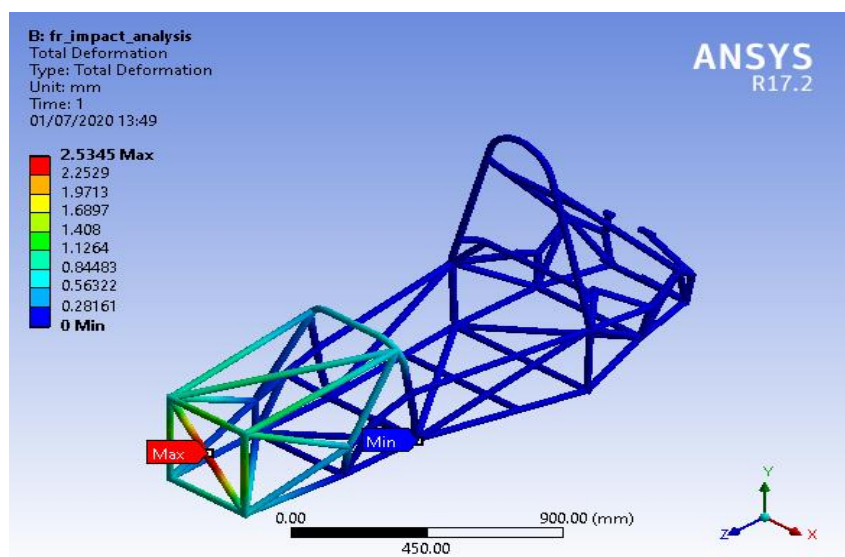

Figure 5 Deformation Analysis of Front Impact structure 


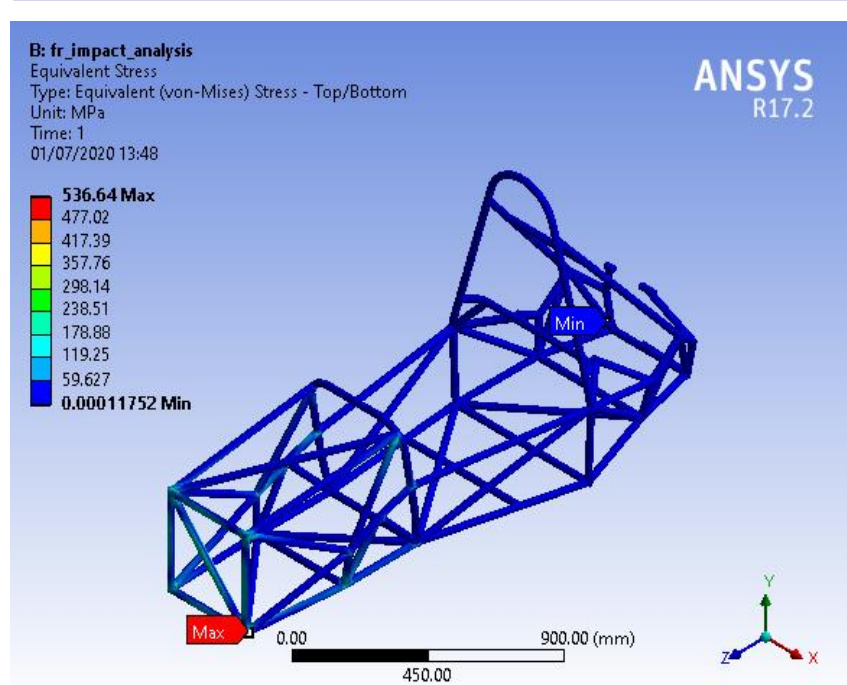

Figure 6 Von Mises Stress Analysis of Front Impact Structure

\section{Result}

TABLE 8

\begin{tabular}{|c|c|}
\hline Maximum Deformation & $2.5345 \mathrm{~mm}$ \\
\hline Von Mises & $536.64 \mathrm{MPa}$ \\
\hline Factor of Safety & UTS/WPS $=670 / 536.64=1.24$ \\
\hline
\end{tabular}

\section{TORSIONAL ANALYSIS}

Torsional stiffness is used to determine the torsional stiffness of structure i.e. how much the structure can resist the twisting. It is a very important parameter of any vehicle to resist torsional stresses and deflection during turning, drifting cornering and undulating road surface. It is good to have high torsional stiffness because it permits to preciously control handling parameters by adjusting the suspension parameters. If car is sufficiently stiff under torsional loading, then it will normally withstand bending and longitudinal/lateral bending Torsional rigidity validates/rejects the chassis structure. In this case, chassis is assumed to act as a cantilever with one end fixed and other end free and subjected to torque about its longitudinal axis. Clockwise couple of $3000 \mathrm{~N}$ was applied on front suspension pickup points by fixing rear suspension pickup points.

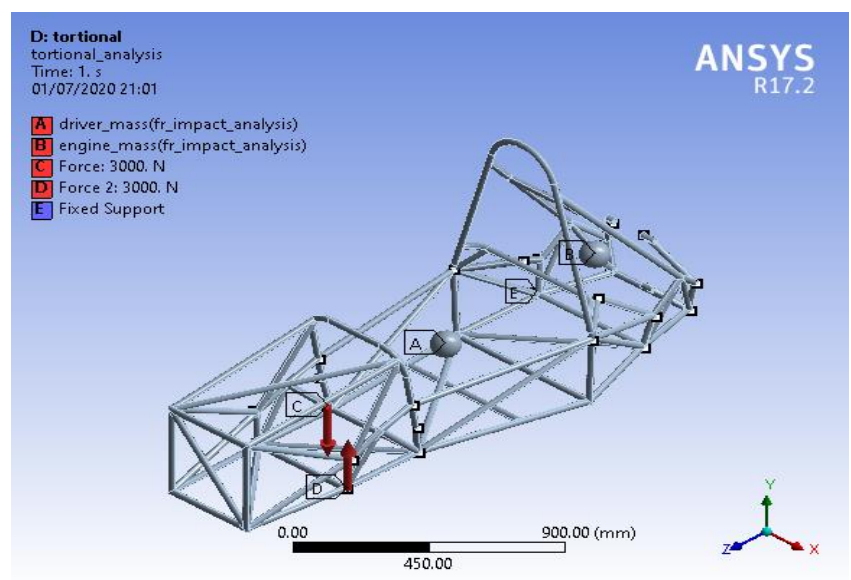

Figure 7 Boundary Conditions for Torsional Analysis
TABLE 9

\begin{tabular}{|c|c|c|}
\hline \multicolumn{2}{|c|}{} & $\begin{array}{c}\text { 3000N (Right side } \\
\text { Front Suspension } \\
\text { mountings in Y axis) } \\
-3000 \text { (Left Side front } \\
\text { Tuspension mountings } \\
\text { in Y axis) }\end{array}$ \\
\hline Boundary Condition & Translational & $\begin{array}{c}\text { Rotational } \\
\text { Displacement }\end{array}$ \\
\hline \multirow{2}{*}{ Front Suspension } & Displacement & X = Free \\
\cline { 2 - 3 } & $\mathrm{X}=$ Free & Y = Free \\
\cline { 2 - 3 } & $\mathrm{Y}=$ Free & $\mathrm{Z}=$ Free \\
\hline \multirow{3}{*}{ Rear Suspension } & $\mathrm{Z}=$ Free & $\mathrm{X}=$ Fixed \\
\cline { 2 - 3 } & $\mathrm{X}=0$ & $\mathrm{Y}=$ Fixed \\
\cline { 2 - 3 } & $\mathrm{Y}=0$ & $\mathrm{Z}=$ Fixed \\
\hline
\end{tabular}

For torsional analysis force of $3000 \mathrm{~N}$ is applied on left side front suspension in up word direction and $3000 \mathrm{~N}$ of force is applied on right side front suspension in down word direction. it produces a couple which apply the torque on chassis the rear suspension mountings are fixed in translational and rotational displacement during torsional analysis This approach adopted in finding an ideal stiffness focused around finding the least stiff the chassis could be before major performance or handling losses would arise. This method was chosen because stiffness is so closely related to vehicle weight, and for a Formula SAE vehicle, weight is the most sensitive parameter on the car.

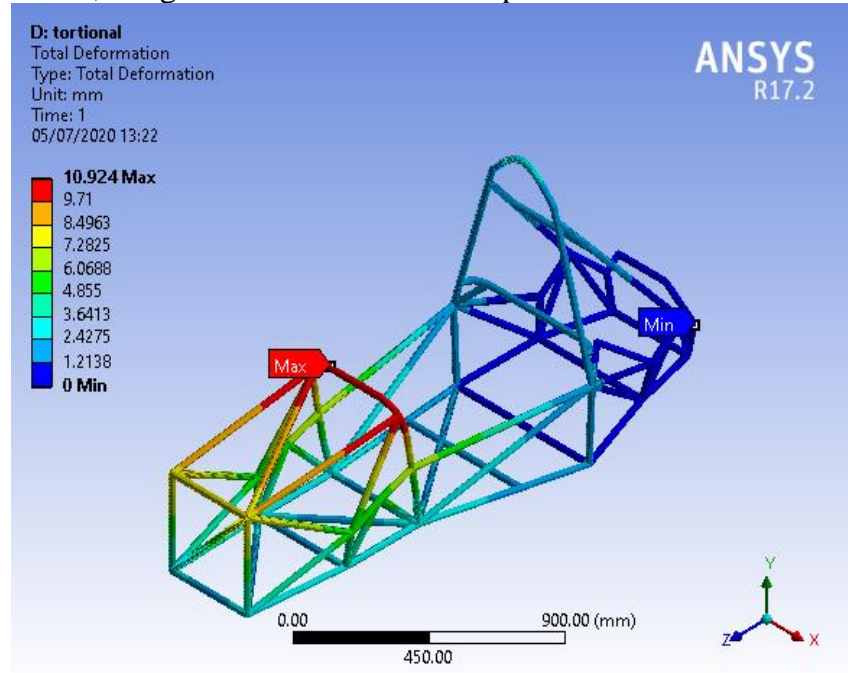

Figure 8 Torsional Deformation Analysis of Chassis

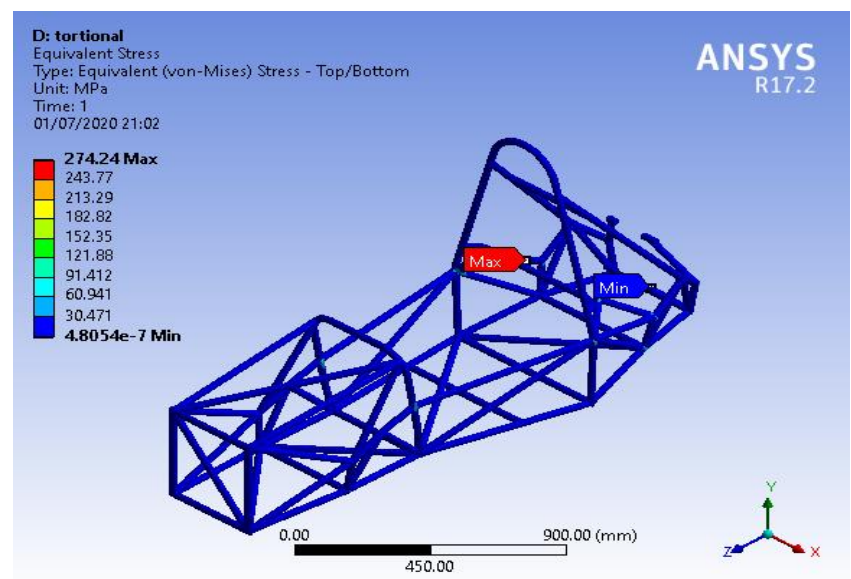

Figure 9 Von Misses Stress due to Torsional deflection 


\section{Initial Assumptions}

Driver weight $=60 \mathrm{~kg}$

Car Weight $=220 \mathrm{~kg}$

Total weight $=280 \mathrm{~kg}$

Force $(F)=3000 \mathrm{~N}$

\section{Calculations}

$>$ Torque $=\mathrm{F} \times(1 / 2)$ Track width $(1)$

$$
\begin{aligned}
& =3000 \times 0.607 \\
& =1821.00 \mathrm{Nm}
\end{aligned}
$$

$>\theta=$ Angle of Deflection

$=$ tan-1 (vertical displacement $/(1 / 2)$ track width)

$=\tan -1(10.924 / 607)$

$=1.031$ degree

$>$ Torsional Stiffness $(\mathrm{k})=$ torque/angle of defection

$=1821.00 / 1.031$

$=1766.27 \mathrm{Nm} /$ degree

\section{Result}

\begin{tabular}{|c|c|} 
TABLE 10 \\
\begin{tabular}{|c|c|}
\hline Maximum Deformation & $10.924 \mathrm{~mm}$ \\
\hline Von Misses Stress & $274.24 \mathrm{MPa}$ \\
\hline Factor of Safety & UTS/WS $=670 / 274.24=2.44$ \\
\hline
\end{tabular}
\end{tabular}

\section{BENDING ANALYSIS}

Vertical bending strength is a strength that shows chassis endurance towards other car components 'weight such as engine, body, wing, drivetrain, and driver under gravitation effect. Vertical bending using car weight to determine whether the frame is strong enough to hold car's weight. Vertical bending strength can be found by applying static force with car's components weight. The one of the ways to calculate bending deflection is rear suspension mountings are acting as fixed supports and a force is acting in vertical direction on front suspension mountings

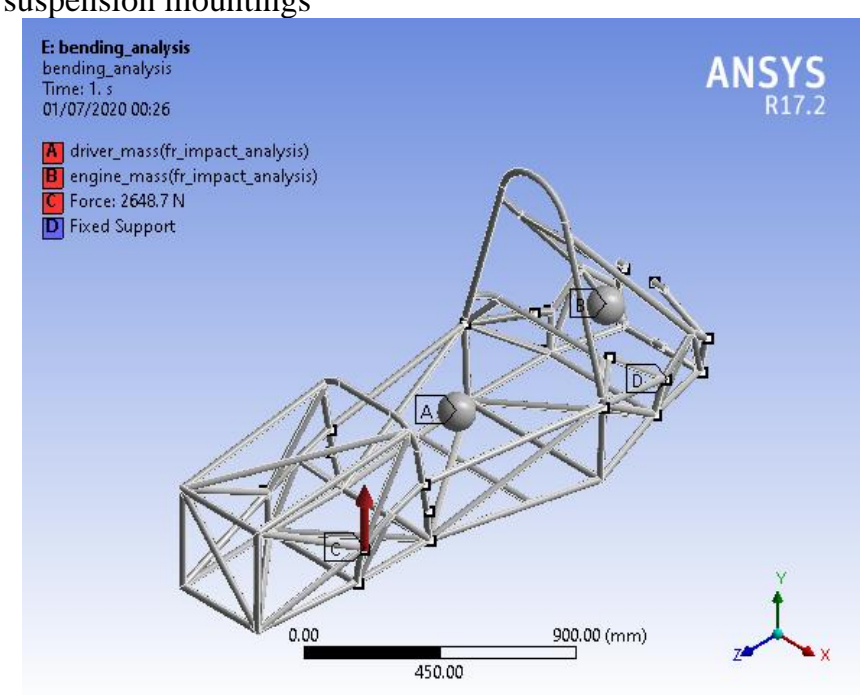

Figure 10 Boundary Conditions for Bending Analysis of Chassis TABLE 11

\begin{tabular}{|c|c|c|}
\hline \multicolumn{2}{|c|}{$\begin{array}{c}\text { Total Force Acting on Chassis (Total } \\
\text { Weight) }\end{array}$} & $2648.7 \mathrm{~N}$ \\
\hline \multirow{2}{*}{$\begin{array}{c}\text { Boundary } \\
\text { Condition }\end{array}$} & $\begin{array}{c}\text { Translational } \\
\text { Deformation }\end{array}$ & $\begin{array}{c}\text { Rotational } \\
\text { Deformation }\end{array}$ \\
\hline \multirow{3}{*}{ Front Suspension } & $\mathrm{X}=$ Free & $\mathrm{X}=$ Free \\
\cline { 2 - 3 } & $\mathrm{Y}=$ Free & $\mathrm{Y}=$ Free \\
\cline { 2 - 3 } & $\mathrm{Z}=$ Free & $\mathrm{Z}=$ Free \\
\hline \multirow{3}{*}{ Rear Suspension } & $\mathrm{X}=0$ & $\mathrm{X}=$ Fixed \\
\cline { 2 - 3 } & $\mathrm{Y}=0$ & $\mathrm{Y}=$ Fixed \\
\cline { 2 - 3 } & $\mathrm{Z}=0$ & $\mathrm{Z}=$ Fixed \\
\hline
\end{tabular}

\section{Calculations}

Bending stiffness of roll cage is calculated by using formula:

$>\mathrm{K}=\mathrm{W} / \mathrm{d}$

$>\mathrm{K}=2648.7 / 1.46$

$>\mathrm{K}=1814.17 \mathrm{~N} / \mathrm{mm}$

Whereas,

$\mathrm{K}=$ Bending stiffness of roll cage.

$\mathrm{W}=$ Applied force

$\mathrm{d}=$ deformation

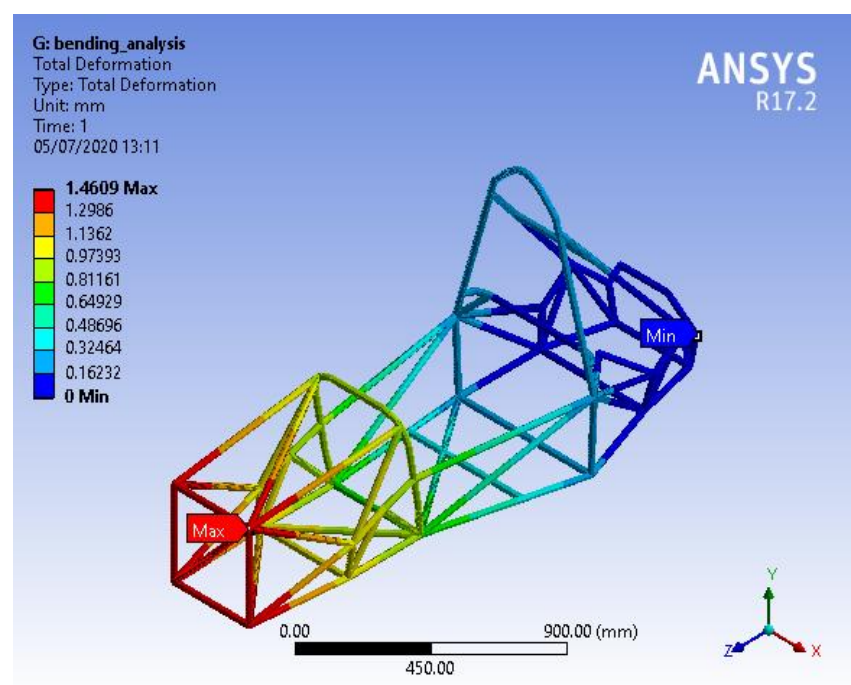

Figure 11 Bending Deformation Analysis of Chassis

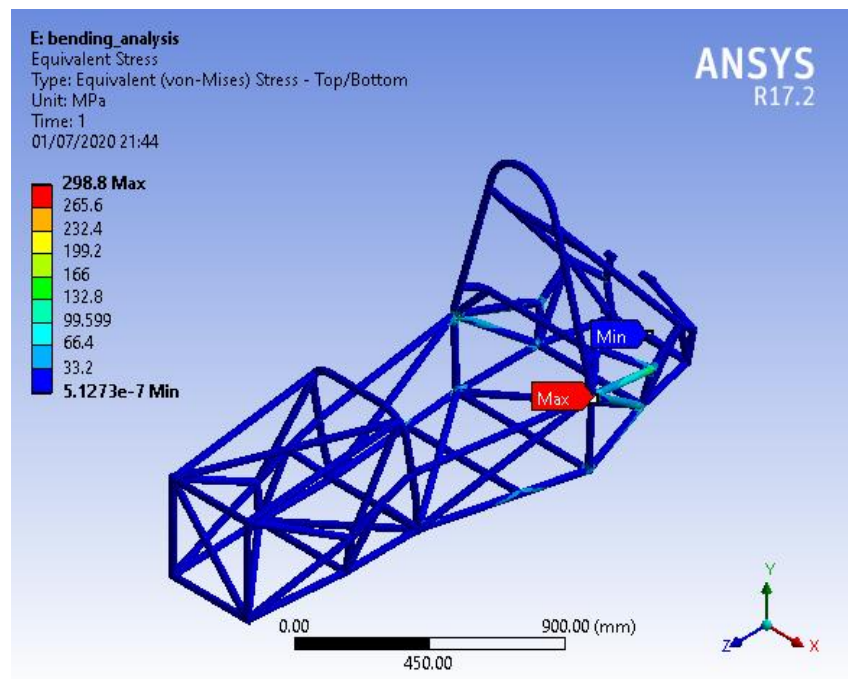

Figure 12 Von Mises Stress due to Bending of chassis 


\section{Result}

\begin{tabular}{|c|c|}
\hline \multicolumn{2}{|c|}{ TABLE 12} \\
\hline Maximum Deformation & $1.46 \mathrm{~mm}$ \\
\hline Von Mises Stress & $298.8 \mathrm{MPa}$ \\
\hline Factor of Safety & UTS/WS $=670 / 298.8=2.24$ \\
\hline
\end{tabular}

\section{MODAL ANALYSIS}

Modal analysis is the study of the dynamic properties of structures under vibrational excitation. Modal analysis is the field of measuring and analyzing the dynamic response of structures and or fluids during excitation. In cars it is used to determine natural frequencies of vibrations. Higher the natural frequency better is the structure to sustain Modal analysis determines the mode shape (vibration shape) and frequencies for the particular mode shape of a structure for a free vibration analysis. Normal Modes Analysis, also called eigenvalue analysis or eigenvalue extraction, is technique used to calculate the vibration shapes and associated frequencies that a structure will exhibit. It is important to know these frequencies because if cyclic loads are applied at these frequencies, the structure can go into a resonance condition that will lead to catastrophic failure. It is also important to know the shapes in order to make sure that loads are not applied at points that will cause the resonance condition. Modal analysis has been done to ensure that the natural frequency of the roll cage does not match the natural frequency of the engine.

Natural frequency of engine is $42 \mathrm{~Hz}$.

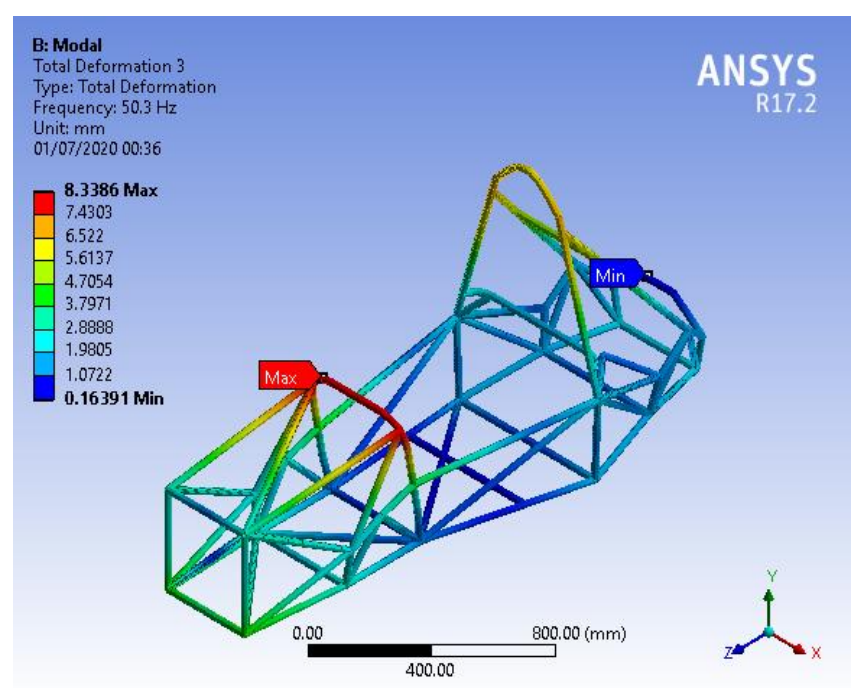

Figure 13 Modal Analysis of Chassis

TABLE 12

\begin{tabular}{|c|c|c|}
\hline No Modes & Frequency (Hz) & Deformation(mm) \\
\hline 1$)$ & 50.3 & 8.3386 \\
\hline 2$)$ & 81.876 & 7.0605 \\
\hline 3$)$ & 87.16 & 9.3975 \\
\hline 4$)$ & 102.72 & 11.666 \\
\hline 5$)$ & 103.58 & 11.904 \\
\hline 6$)$ & 131.01 & 12.457 \\
\hline 7$)$ & 143.23 & 14.145 \\
\hline 8$)$ & 145.35 & 10.997 \\
\hline 9$)$ & 161.00 & 12.209 \\
\hline 10$)$ & 168.13 & 16.877 \\
\hline
\end{tabular}

The fundamental of modal analysis using measured frequency response function data is about curving fitting the data using a predefined mathematical model of the measured structure. This model assumes the number of DOFs of the structure, damping measured frequency range type and possibly the number of vibrations modes within the measured frequency range.

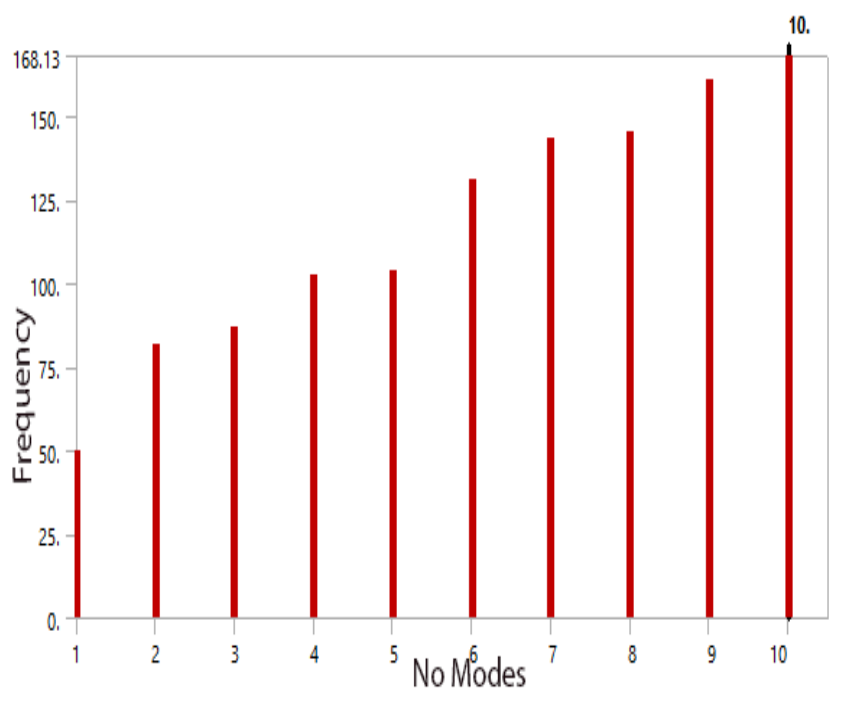

Figure 14 Graph of Frequency Vs No modes

\section{CONCLUSION}

Overall goals for the chassis included, increasing torsional rigidity and decrease weight, deformation. Chassis should perform at an optimum level. The results gained in this section show that the chassis will experience very minimal deflections under race conditions. This is also going to allow the chassis to perform at an optimum level in conjunction with the rest of the vehicle setup. Like any vehicle, the chassis is the backbone of the system. Every critical component relies on the chassis either directly or indirectly. The driver of the vehicle also relies on the chassis for protection in the event of an accident. This dissertation covers the procedures that were used to successfully design and construct a functional chassis

\section{REFERENCES}

[1] William F. Milliken and Douglas L. Milliken, "RACE CAR VEHICLE DYNAMICS", Society of Automotive Engineers Inc., pg. 673-667, 1995

[2] Daryl L. Logan, "FIRST COURSE IN FINITE ELEMENT ANALYSIS",

[3] Thomas D. Gillespie. Fundamentals of Vehicle Dynamics. Society of Automotive Engineers, Inc.

[4] Herbs Adams, "CHASSIS ENGINEERING “,

[5] William B. Riley and Albert R. George, Cornell University, "Design, Analysis and Testing of a Formula SAE Car Chassis", 2002

[6] Carroll Smith," TUNE TO WIN",1978, Inc.

[7] ] Mohammad Al Bukhari Marzuki, Mohd Arzo Abu Bakar and Mohammad Firdaus Mohammed Azmi, "Designing Space Frame Race Car Chassis Structure Using Natural Frequencies Data from Ansys Mode Shape Analysis" ,International journal of information systems and engineering, April 2015 